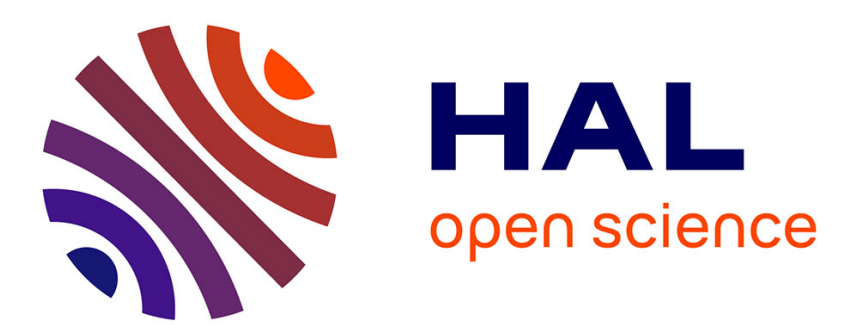

\title{
Monitoring and simulations of hydrolysis in epoxy matrix composites during hygrothermal aging
}

Jalal El Yagoubi, Gilles Lubineau, Abderrazak Traidia, Jacques Verdu

\section{To cite this version:}

Jalal El Yagoubi, Gilles Lubineau, Abderrazak Traidia, Jacques Verdu. Monitoring and simulations of hydrolysis in epoxy matrix composites during hygrothermal aging. Composites Part A: Applied Science and Manufacturing, 2014, 68, pp.184-192. 10.1016/j.compositesa.2014.10.002 . hal-01086406

\section{HAL Id: hal-01086406 https://hal.science/hal-01086406}

Submitted on 24 Nov 2014

HAL is a multi-disciplinary open access archive for the deposit and dissemination of scientific research documents, whether they are published or not. The documents may come from teaching and research institutions in France or abroad, or from public or private research centers.
L'archive ouverte pluridisciplinaire HAL, est destinée au dépôt et à la diffusion de documents scientifiques de niveau recherche, publiés ou non, émanant des établissements d'enseignement et de recherche français ou étrangers, des laboratoires publics ou privés. 


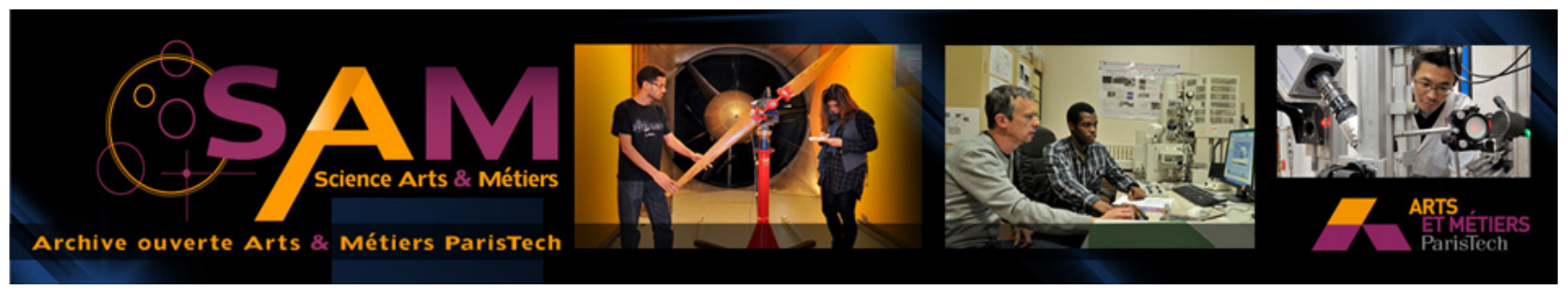

Science Arts \& Métiers (SAM)

is an open access repository that collects the work of Arts et Métiers ParisTech researchers and makes it freely available over the web where possible.

This is an author-deposited version published in: http://sam.ensam.eu

Handle ID: .http://hdl.handle.net/10985/8969

\section{To cite this version :}

Jalal EL YAGOUBI, Gilles LUBINEAU, Abderrazak TRAIDIA, Jacques VERDU - Monitoring and simulations of hydrolysis in epoxy matrix composites during hygrothermal aging - Composites: Part A - Vol. 68, p.184-192 - 2014 


\title{
Monitoring and simulations of hydrolysis in epoxy matrix composites during hygrothermal aging
}

\author{
Jalal El Yagoubi ${ }^{\mathrm{a}, \mathrm{b}, *}$, Gilles Lubineau ${ }^{\mathrm{a}}$, Abderrazak Traidia ${ }^{\mathrm{a}}$, Jacques Verdu ${ }^{\mathrm{c}}$ \\ ${ }^{a}$ King Abdullah University of Science and Technology (KAUST), Division of Physical Sciences and Engineering, COHMAS Lab, Thuwal 23955-6900, Saudi Arabia \\ ${ }^{\mathrm{b}}$ Univ. Bordeaux, I2M, UMR 5295, F-33400 Talence, France \\ ${ }^{\mathrm{c}}$ Arts et Metiers ParisTech, Laboratoire PIMM, 151 Boulevard de l'Hopital, 75013 Paris, France
}

Keywords:

A. Theromosetting resin

A. Polymer-matrix composites (PMCs)

D. Chemical analysis

B. Environmental degradation

\begin{abstract}
A B S T R A C T
In this paper, we studied the water transport in thermoset matrices. We used Fourier Transform Infrared analysis (FTIR) during sorption/desorption experiments to investigate the interaction between sorbed water and the epoxy network. Our results demonstrated that the polymer matrix undergoes hydrolysis. We found that the chemical species involved in the reaction process was the residual anhydride groups. These results support the physical basis of the three-dimensional (3D) diffusion/reaction model. We finally showed that this model is able to reproduce multi-cycle sorption/desorption experiment, as well as water uptake in hybrid metal/epoxy samples. We simulated the 3D distributions of the diffusing water and the reacted water.
\end{abstract}

\section{Introduction}

The use of fiber-reinforced polymers in aircraft fuselage allows aircraft manufacturers to develop lightweight and multifunctional composite structures with high mechanical performance along with resistance to chemical and physical degradation. Metal reinforcements [1] or conductive nano fillers [2] need to be added to the Carbon Fiber Reinforced Composites (CFRP) to enhance their electrical and thermal properties. One way to do this is co-bonding a expanded foil to the external side of the composite using an epoxy-based adhesive. Under service conditions, these hybrid structures can be exposed to humidity and temperature cycles. A durability assessment of these materials is necessary to end up with optimized structure designs and maintenance strategies. The phenomenological overview of the problem presented by Lubineau et al. [3], highlighted the various couplings involved in the aging process. Water uptake leads to degradation of mechanical properties [4,5] as well as swelling [6-8] and can additionally lead to chemical degradation [9] or microstructural changes [10]. Then, multiple aging mechanisms can combine to result in damage of the matrix and the interfaces.

A crucial starting point in understanding the aging of hybrid composites is to perform modeling and simulation of the moisture

\footnotetext{
* Corresponding author at: Univ. Bordeaux, I2M, UMR 5295, F-33400 Talence, France. Tel.: +33 (0) 605105998.

E-mail address: jalal.el-yagoubi@u-bordeaux.fr (J. El Yagoubi).
}

sorption process in the epoxy network, that are both accurate and robust to long-term extrapolation. This requires an in-depth physical understanding to validate the modeling approach. Epoxy resins can exhibit complex sorption behaviors that cannot be captured by the Fickian model [11]. Sorption experiments conducted on several epoxy systems often reveal anomalies in the mass uptake of neat polymer specimens [10,12-15]. Explaining such behaviors requires distinguishing between the different forms of water that can be found in the wet polymer. Part of the sorbed water exists as molecular water and is either free in the network and the microvoids $[10,16]$ or involved in physical interactions with polymer chains or other water molecules $[16,17]$. The other part of the water is involved in hydrolysis reactions [9,15]. Hence, the overall amount of sorbed water cannot be considered as a unique aging indicator because these various species have different effects on the polymer. It is therefore necessary to examine the sorption mechanisms and establish relationships between the types of water and the subsequent evolution of the material's properties and swelling. For this purpose, the spectroscopy techniques can be used to investigate the nature of the water sorption mechanisms. Nuclear Magnetic Resonance (NMR) can track physical interactions [16,17] while Fourier Transform Infrared (FTIR) techniques are suitable to investigate chemical effects $[9,18,19]$. In [20], the authors quantified the changes in concentrations of the reaction products from their IR peaks area. In addition, Leger et al. [10] showed that Scanning Electron Microscopy (SEM) reveals morphological changes. 
We proposed and identified in [21] a general modeling framework for prediction of the spatial distribution of species concentrations. This model was based on a competitive diffusion/reaction scheme and relied on a heterogeneous description of the material in which local model parameters depend on both the local amounts of diffusive and reacted water. Yet, it is clear that the retained approach is a generic scheme that accounts for different possible underlying mechanisms. As a result, it is necessary to refine the phenomenology in order to elucidate the mechanisms responsible for the non-classical sorption behaviors of polymer matrix composites. The objective of this paper is to validate our approach by (1) clarifying the physical basis of the model by monitoring chemical and microstructural changes (FTIR, SEM), (2) and by demonstrating the capability of the model in complex situations. In particular, we investigate water uptake under cyclic humidity conditions. Also, we note that the model's parameters are local properties such that this framework allows us to assess moisture uptake in a complex structure. We study the particular case of the water transport in an epoxy matrix with a three-dimensional (3D) metal network in this work.

In the next section, the bases of the diffusion-reaction scheme are reviewed. We next describe, in Section 3, an anhydride-cured epoxy resin and a metal reinforced polymer (expanded metal foil impregnated in an epoxy matrix). We give details of the experimental procedures in Section 4, with particular focus on gravimetric analysis and spectroscopic techniques (FTIR). We monitored the morphological and chemical changes in the polymer using electron microscopy and FTIR. We used the FTIR results to discuss the reactive mechanisms involved in the aging of the epoxy matrix. We finally illustrate numerical simulations of the fully coupled diffusion-reaction process in complex configurations.

\section{A non-homogeneous diffusion-reaction scheme for moisture uptake}

The experimental results reported in [21] revealed that the epoxy system studied here does not exhibit Fickian behavior. The proposed diffusion-reaction scheme describes water transport as a competition between (1) diffusion, which can involve several fundamental mechanisms (free volume, water/polymer interactions) and (2) a reactive process that can induce certain changes in the polymer (structure or microstructure). The diffusion is fully coupled with the reaction through non-constant Fickian parameters. We consider a phenomenological description of the reactive process, based on a first-order chemical reaction (Eq. (1)) between diffusing water, $w\left(\mathrm{~mol} / \mathrm{m}^{3}\right)$, and a reactive substrate, $R\left(\mathrm{~mol} / \mathrm{m}^{3}\right)$, leading to the production of a complex, $Y\left(\mathrm{~mol} / \mathrm{m}^{3}\right)$ :

$w+R \leftrightarrows Y$

The governing equations of the proposed phenomenological model were detailed in [21] and are briefly reviewed below:

\section{Conservation equations}

$\frac{\partial w}{\partial t}=-\operatorname{div}(\underline{j})+r_{w}$

where $j$ is the mass flux of diffusing water and $r_{w}$ describes the formation/dissociation kinetics of the complex.

$\frac{\partial Y}{\partial t}=r_{Y}$

$\frac{\partial R}{\partial t}=r_{R}$

\section{Constitutive equation}

\section{Diffusion law}

$\underline{j}=-D(Y)\left(\underline{\nabla} w-\frac{w}{w_{s}(Y)} \underline{\nabla} w_{s}(Y)\right)$

where $w_{s}$ is the maximum reachable water concentration. The diffusivity, $D(Y)$, and the solubility, $S_{0}+S_{1} \cdot Y$, are dependent on the progress of the reaction.

$D(Y)=D_{0}+D_{1} \cdot Y$

$w_{s}(Y)=\left(S_{0}+S_{1} \cdot Y\right) a^{e} p_{\text {sat }}$

where $a^{e}$ is the water activity in the environment and $p_{\text {sat }}$ is the saturation vapor pressure in air.

\section{Reaction kinetics}

$r_{w}=-k_{h}(T) w R+k_{r}(T) Y$

$r_{R}=-k_{h}(T) w R+k_{r}(T) Y$

$r_{Y}=k_{h}(T) w R-k_{r}(T) Y$

$k_{h}$ and $k_{\mathrm{r}}$ are the rate constants for the forward and the reverse reactions, respectively. From a general viewpoint, the temperature effects can be taken into account [21]. Hence, the diffusivity and the solubility obey to an Arrhenius-type law, and the two rate constants are also temperature dependent.

We previously described an optimization procedure to identify the model parameters that are summarized in Table 1 [21].

We can envisage several physical interpretations to explain our experimental observations. First, the second stage in the sorption curve could be attributed to hydrolysis of reactive groups available in anhydride cross-linked epoxy systems. Those can be either (1) the residual epoxy or anhydride groups that are in excess [15,22] or (2) the ester groups [20].

Nevertheless, microstructural changes, such like microcavities or microcracks, could be another responsible mechanism [10]. We note that, despite they tremendously differ from a physics viewpoint, all these mechanisms could be generalized in an apparent diffusion/reaction scheme as in [21]. In this paper, we attempted to validate the diffusion-reaction scheme by answering some of the questions regarding the physical foundations of the model. This required a suitable characterization of the epoxy system under investigation, which is detailed in the next section.

\section{Materials}

\subsection{The anhydride-cured epoxy system}

The epoxy-based matrix was the commercially available EPOLAM 2063 system (supplied by Axson Technologies). It consisted

Table 1

Parameters of the diffusion-reaction model: values identified using the optimization process [21].

\begin{tabular}{lll}
\hline Parameter & Unit & Optimal value \\
\hline$D_{0}$ & $\mathrm{~m}^{2} \mathrm{~s}^{-1}$ & $4.5 \times 10^{-12}$ \\
$S_{0}$ & $\mathrm{~mol} \mathrm{~m}^{-3} \mathrm{~Pa}^{-1}$ & 0.0597 \\
$D_{1}$ & $\mathrm{~mol}^{-1} \mathrm{~m}^{5} \mathrm{~s}^{-1}$ & $-1.24 \times 10^{-14}$ \\
$S_{1}$ & $\mathrm{~Pa}^{-1}$ & $1.676 \times 10^{-4}$ \\
$R_{0}$ & $\mathrm{~mol} \mathrm{~m}^{-3}$ & $4.5 \times 10^{3}$ \\
$k_{h}$ & $\mathrm{~mol}^{-1} \mathrm{~m}^{3} \mathrm{~s}^{-1}$ & $8.535 \times 10^{-10}$ \\
$k_{r}$ & $\mathrm{~mol} \mathrm{~m}^{-3}$ & $6.5 \times 10^{3}$ \\
\hline$k_{h}$ & & \\
\hline
\end{tabular}


of an epoxy resin crosslinked with an anhydride hardener. With the resin and the hardener available at the liquid state, we characterized the initial products separately.

- The resin part of the system was a mixture of several epoxy monomers. The epoxy index was equal to $5.73 \mathrm{~mol}$ of epoxy per $\mathrm{kg}$ of resin, as determined by titration with perchloric acid following the NF-EN ISO 3001 standard. The epoxy equivalent weight (EEW) was then equal to $174.5 \mathrm{~g} / \mathrm{mol}$. Liquid chromatography combined with mass spectroscopy (LC-MS) revealed that the epoxy blend was mostly comprised of cycloaliphatic epoxy resin (Fig. 1(a), $M_{C A}=252 \mathrm{~g} / \mathrm{mol}$ ) and a smaller amount of oligomers of diglycidyl ether of bisphenol-A resin (Fig. 1(b), $M_{D}=340+284 n \mathrm{~g} / \mathrm{mol}$ ), with $n$ between 0 and 2 . The two prepolymers were bifunctional and the average molecular weight was $349 \mathrm{~g} / \mathrm{mol}$.

The FTIR spectrum of the uncured resin, obtained using a Nicolet is10 infrared spectrometer (Thermo Scientific) in the range of $4000-500 \mathrm{~cm}^{-1}$ with $2 \mathrm{~cm}^{-1}$ resolution, is given in Fig. 2 . The assignments of the main IR bands are presented in Table 2.

- The hardener, shown in Fig. 3, was a commercial acid anhydride (Nadic Methyl Anhydride, $M_{A N}=178 \mathrm{~g} / \mathrm{mol}$ ). The FTIR spectrum of the liquid hardener, in the range of 4000 to $500 \mathrm{~cm}^{-1}$ with $2 \mathrm{~cm}^{-1}$ resolution, is shown in Fig. 4. The assignments of the main IR bands are presented in Table 3.

\subsection{Neat epoxy samples}

The resin was mixed with the anhydride hardener with a volume ratio of $1: 1$ (100:107 mass ratio). Both the resin and the hardener were mixed and stirred at $75{ }^{\circ} \mathrm{C}$ for $15 \mathrm{~min}$. Then, the resin was poured into a flexible thermoplastic mold and we degassed the blend inside a vacuum chamber (Struers Citovac) at 0.1 bar pressure at room temperature. The epoxy preparation was cured by following the two-step cycle recommended by the supplier. First, the blend was heated at $80^{\circ} \mathrm{C}$ and for $6 \mathrm{~h}$ and then cooled down to the ambient temperature. After removal from the molds, the samples were heated to $180^{\circ} \mathrm{C}$ and post-curing was completed after $4 \mathrm{~h}$. Finally, $10 \mathrm{~mm}$ by $15 \mathrm{~mm}$ samples were obtained by cutting the raw plates using a diamond saw. The thickness of each specimen was adjusted by grinding the surfaces with SiC abrasive paper (\#1000). The samples were then maintained inside a desiccator at room temperature.

\subsection{The metal reinforced polymer}

In addition to neat polymer samples, we also tested heterogeneous material. Expanded metal foils were impregnated under vacuum with the epoxy matrix described in the previous section. Polymer curing and specimen sizing were both rigorously identical to the procedure previously described.

Two types of expanded foil, made either of copper or aluminum, were used to prepare heterogeneous specimens. A schematic and the dimensions of the elementary diamond-shaped pattern of the

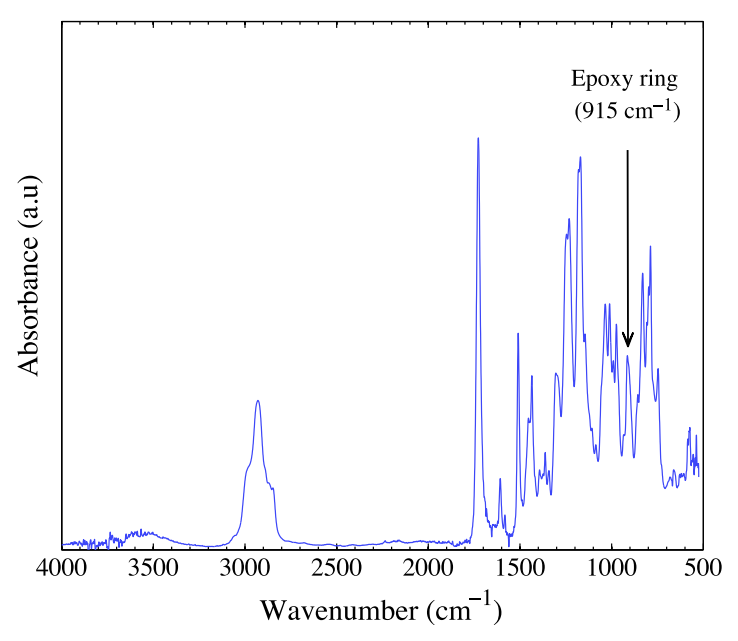

Fig. 2. FTIR analysis of the resin part of EPOLAM 2063.

Table 2

Assignments of the main FTIR bands of the resin part.

\begin{tabular}{ll}
\hline Wavenumber $\left(\mathrm{cm}^{-1}\right)$ & Assignment \\
\hline 2929 & Epoxy $v(\mathrm{CH})$ \\
1727 & $\mathrm{C}=\mathrm{O}($ cycloaliphatic resin $)$ \\
1508 & $\mathrm{C}=\mathrm{C}$ (aromatic nucleus) \\
915 & Epoxy ring \\
\hline
\end{tabular}

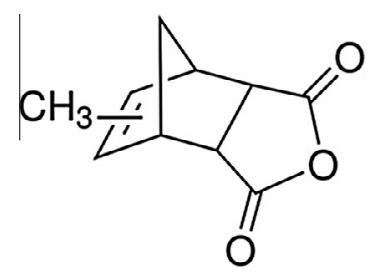

Fig. 3. Anhydride hardener.

expanded foil are given in Fig. 5 and Table 4, respectively. Fig. 6 shows optical micrographs of the cross-sections of metal/epoxy samples.

The volume fraction of metal $\left(f_{m}\right)$ for each sample was estimated by means of density measurements using Eq. (11):

$f_{m}=\frac{\rho_{t}-\rho_{p}}{\rho_{m}-\rho_{p}}$

where $\rho_{m}, \rho_{p}$ and $\rho_{t}$ are the densities of the metal $\left(\rho_{m}=8940 \mathrm{~kg} \mathrm{~m}^{-3}\right.$ for copper and $\rho_{m}=2700 \mathrm{~kg} \mathrm{~m}^{-3}$ for aluminum), the polymer $\left(\rho_{p}=1200 \mathrm{~kg} \mathrm{~m}^{-3}\right)$ and the composite material. Table 5 presents the estimated volume fraction of metal for the prepared specimens.<smiles>O=C(OCC1CCC2OC2C1)C1CCC2OC2C1</smiles>

(a) Cycloaliphatic epoxy resin<smiles>CCOc1ccc(C(C)(C)c2ccc(OCC(O)COc3ccc(C(C)(C)c4ccc(OCC5CO5)cc4)cc3)cc2)cc1</smiles>

(b) Diglycidyl ether of bisphenol A

Fig. 1. Main epoxy monomers in the resin part of EPOLAM 2063. 


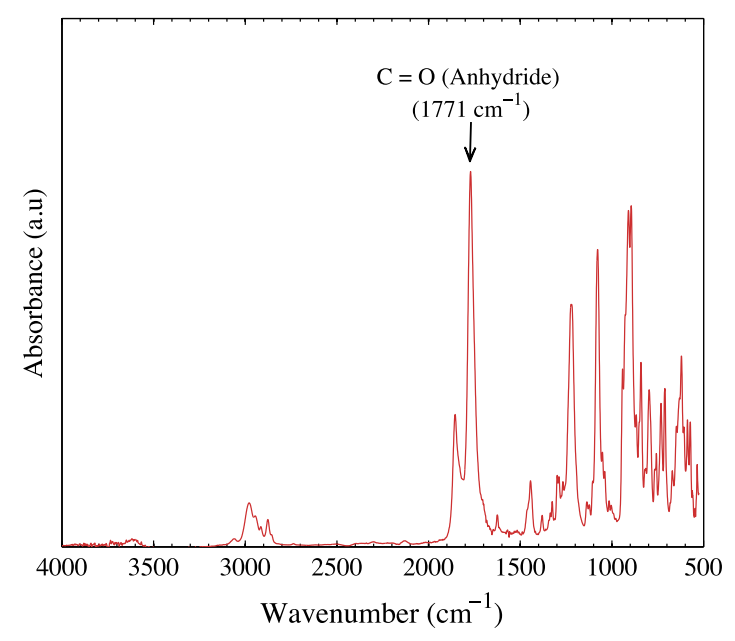

Fig. 4. FTIR analysis of the hardener part of EPOLAM 2063.

Table 3

Assignments of the main FTIR bands of the hardener part.

\begin{aligned} & \hline Wavenumber $\left(\mathrm{cm}^{-1}\right)$ Assignment \\ & \hline 1856$v_{s}(\mathrm{C}=0)$ Anhydride \\ & 1771 Anhydride ring \\ & 1078 Anhydride ring \\ & 915 Anhydride ring \\ & \hline\end{aligned}

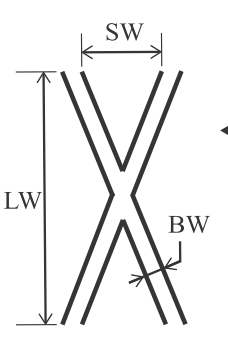

Elementary pattern

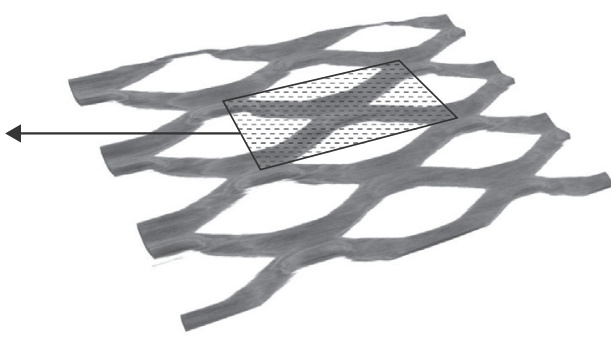

X-Ray Tomography
Fig. 5. A schematic of the diamond-shaped pattern and an X-ray tomograph of the expanded metal foil.

Table 4

Dimensions of the diamond-shaped pattern in the expanded metal foil.

\begin{tabular}{lll}
\hline Metal $(\mathrm{mm})$ & Copper & Aluminum \\
\hline LW & 1.98 & 0.9 \\
SW & 0.93 & 0.4 \\
BW & 0.36 & 0.2 \\
\hline
\end{tabular}

\section{Experimental techniques}

\subsection{Gravimetric analysis}

The gravimetric analysis was conducted on an IGASorp-HT system (Hiden Isochema). This instrument allowed us to monitor the mass uptake and the sorption kinetics accurately by means of a microbalance with $0.1 \mu \mathrm{g}$ resolution and precise control of both temperature and humidity.

Samples were introduced inside a chamber on a stainless steel mesh sample holder that was $15 \mathrm{~mm}$ in diameter. The testing procedure was as follows. Prior to the start of the absorption

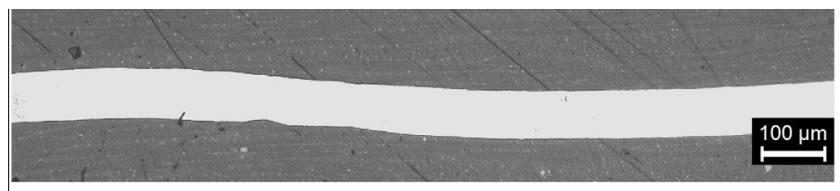

(a)

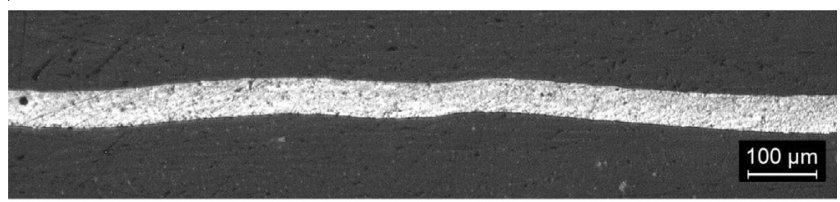

(b)

Fig. 6. Optical micrographs of cross-sections (top and bottom are the edges exposed to moist air) of metal/epoxy composites: (a) copper and (b) aluminum.

analysis, samples were first dried until equilibrium was reached. Then, a stream of moist air was circulated at $250 \mathrm{~mL} / \mathrm{min}$ in the chamber. The partial water pressure was controlled by mixing a dry nitrogen flow with a wet air flow.

Static tests, at a constant temperature $\left(50^{\circ} \mathrm{C}\right)$, consisted in a first sorption stage $(60 \% \mathrm{RH})$ lasting $24 \mathrm{~h}$ followed by a desorption stage $(0 \% \mathrm{RH})$ of $24 \mathrm{~h}$ duration. Neat epoxy samples and metal/ epoxy composites were both tested under these conditions.

Additionally, cyclic tests were performed at a constant temperature $\left(50^{\circ} \mathrm{C}\right)$ under changing humidity as depicted in Fig. 7. The humidity level was maintained for $24 \mathrm{~h}$ at $60 \% \mathrm{RH}$ and then it oscillated between $20 \% \mathrm{RH}$ and $60 \% \mathrm{RH}$ following a two-hours-period stepwise rectangular cycle. The test was stopped after 12 cycles. Only neat epoxy samples were tested under these conditions.

The overall mass uptake, $m_{w}^{\exp }$ (Eq. (12)), is defined as the ratio of the mass of water absorbed by the resin, $\Delta m$ (Eq. (13)), to the mass of the initial sample at the dried state, $m_{0}$ :

$m_{w}^{\exp }=\frac{\Delta m(t)}{m_{0}}$

where:

$\Delta m(t)=m(t)-m_{0}$

\subsection{FTIR analysis of the aging process}

FTIR was performed to gain a global characterization of the chemical evolution of neat epoxy samples under short-term aging. The equipment used was the Nicolet is10. FTIR was performed in the ATR mode at the surface located at almost the mid-plane (half the thickness), which was revealed by dry-grinding. Each spectrum was collected between 4000 and $700 \mathrm{~cm}^{-1}$ with 64 scans at a spectral resolution of $4 \mathrm{~cm}^{-1}$. Fig. 8 shows that samples \#S1 to \#S7 were tested at seven different stages during sorption and desorption. Table 6 lists the experimental conditions for all the sorption experiments.

\subsection{Scanning electron microscopy}

Neat epoxy specimens aged for different lengths of time (Table 6) were broken under liquid nitrogen and sputter coated

Table 5

Characteristics of the metal/epoxy samples.

\begin{tabular}{llll}
\hline Designation & $\begin{array}{l}\text { Thickness } \\
(\mu \mathrm{m})\end{array}$ & $\begin{array}{l}\text { Density } \\
\left(\mathrm{kg} \mathrm{mol}^{-3}\right)\end{array}$ & $\begin{array}{l}\text { Vol. fraction of metal } f_{m} \\
(\%)\end{array}$ \\
\hline $\begin{array}{c}\text { Copper/epoxy } \\
\text { Aluminum/ } \\
\text { epoxy }\end{array}$ & 210 & 2000 & 10.5 \\
\hline
\end{tabular}




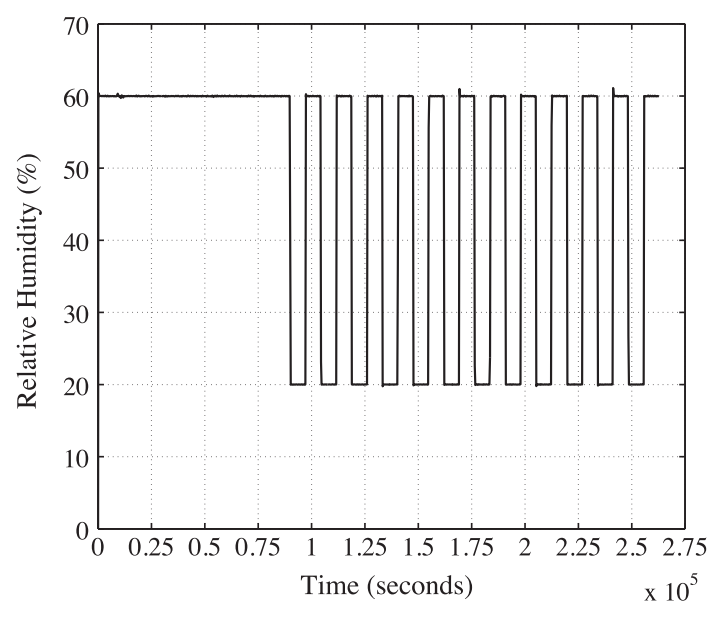

Fig. 7. Actual humidity conditions applied during the sorption experiment under cyclic conditions (temperature $=50^{\circ} \mathrm{C}$ ).

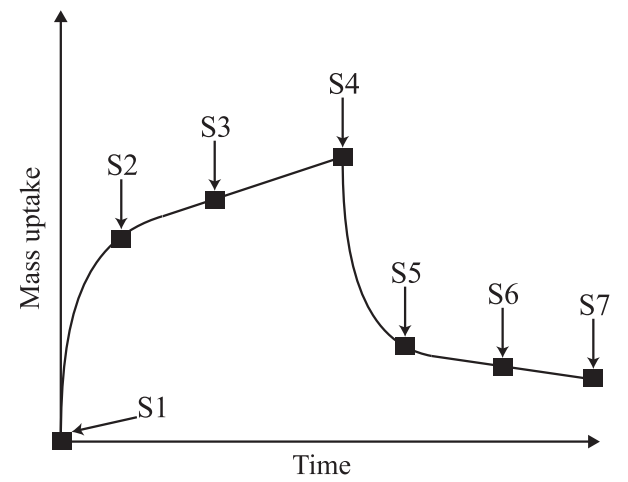

Fig. 8. Schematic representation of a sorption-desorption test showing the seven stages at which FTIR spectra were collected.

Table 6

Experimental conditions for all aging experiments.

\begin{tabular}{|c|c|c|c|}
\hline Designation & $\begin{array}{l}\text { Thickness } \\
(\mu \mathrm{m})\end{array}$ & Type of test & Humidity conditions \\
\hline So & $545 \pm 5$ & Gravimetry & Cyclic RH (Fig. 15) \\
\hline S1 & $530 \pm 5$ & Gravimetry + FTIR/SEM & Drying \\
\hline S2 & $530 \pm 5$ & Gravimetry + FTIR/SEM & $6 \mathrm{~h}$ at $60 \% \mathrm{RH}$ \\
\hline S3 & $530 \pm 5$ & Gravimetry + FTIR/SEM & $12 \mathrm{~h}$ at $60 \% \mathrm{RH}$ \\
\hline S4 & $530 \pm 5$ & Gravimetry + FTIR/SEM & $24 \mathrm{~h}$ at $60 \% \mathrm{RH}$ \\
\hline S5 & $530 \pm 5$ & Gravimetry + FTIR/SEM & $\begin{array}{l}24 \mathrm{~h} \text { at } \\
60 \% \mathrm{RH}+\text { Drying } 6 \mathrm{~h}\end{array}$ \\
\hline S6 & $530 \pm 5$ & Gravimetry + FTIR/SEM & $\begin{array}{l}24 \mathrm{~h} \text { at } \\
60 \% \mathrm{RH}+\text { Drying } 12 \mathrm{~h}\end{array}$ \\
\hline S7 & $530 \pm 5$ & Gravimetry + FTIR/SEM & $\begin{array}{l}24 \mathrm{~h} \text { at } \\
60 \% \mathrm{RH}+\text { Drying } 24 \mathrm{~h}\end{array}$ \\
\hline
\end{tabular}

with a thin gold film. Then, the cross-section was examined using electron microscopy (FEI Nova NanoSEM 630).

\section{Numerical simulations}

The diffusion-reaction model was implemented using COMSOL Multiphysics 4.2a Software and we reproduced virtually the sorption experiments described in Section 3. The evolution of the concentration fields ( $w, R$ and $Y$ ) were simulated. Then, neglecting the swelling of the material, we derived the mass ratio of the overall absorbed water from the average concentrations of $\mathrm{Y}$ and $w$ in the whole domain, $\Omega$, according to Eq. (14). $m_{w}^{\text {num }}=\frac{\Delta m}{m_{0}}=\frac{M_{\mathrm{H}_{2} \mathrm{O}} \int_{\Omega} w+Y d V}{\rho_{0} V_{0}}$

where $\rho_{0}=1200 \mathrm{~kg} \mathrm{~m}^{-3}$ is the initial density of the polymer and $M_{\mathrm{H}_{2} \mathrm{O}}=18 \times 10^{-3} \mathrm{~kg} / \mathrm{mol}$ is the molar mass of water.

\subsection{One-dimensional simulations}

For the simulations with neat epoxy material, we considered a one-dimensional geometry because differences with three-dimensional computations were negligible. The obvious symmetry at the mid-plane was taken into account and only half of the thickness was meshed. Hence, conservation equations (Eqs. (2)-(4)) were solved inside a one-dimensional domain, $\Omega$ (Fig. 9). At half the thickness, which consists of a single point, we applied a zero flux boundary condition. At the interface between the polymer and the humid air $(\partial \Omega)$ which also consists of a single point, the chemical potential of water in both media is equal at equilibrium. Therefore, the water concentration, $w$, was assumed to follow Henry's law (Eq. (15)) at this boundary. Water activity $\left(a^{e}\right)$ was a function of time and was set in accordance with the experimental conditions previously described (sorption-desorption test or cyclic humidity conditions). The local concentration of Y at the air-polymer boundary is then controlled by the Ordinary Differential Equations (Eqs. (3) and (4)) describing the reaction process.

$w=S a^{e} p_{\text {sat }} \quad \forall \underline{M} \in \partial \Omega, \quad \forall t$

The initial conditions are summarized in the Eq. (16). First, we assumed that the material was dry before the start of the gravimetric experiments. Although [23] reported that the polymer can exhibit a two-phase microstructure with a crosslinking gradient, we assumed as an approximation that the initial field of reactive sites is homogeneous, taking the constant value $R_{0}$ across the whole domain $\Omega$.

$$
\begin{array}{ll}
w=0 & \forall \underline{M} \in \Omega, \quad t=0 \\
Y=0 & \forall \underline{M} \in \Omega, \quad t=0 \\
R=R_{0} & \forall \underline{M} \in \Omega, \quad t=0
\end{array}
$$

\subsection{Three-dimensional simulations}

With regard to the heterogeneous material, we conducted three-dimensional simulations based on the diamond shaped pattern shown in Fig. 10. This pattern was assumed to be a representative volume element since, as mentioned before, edge effects

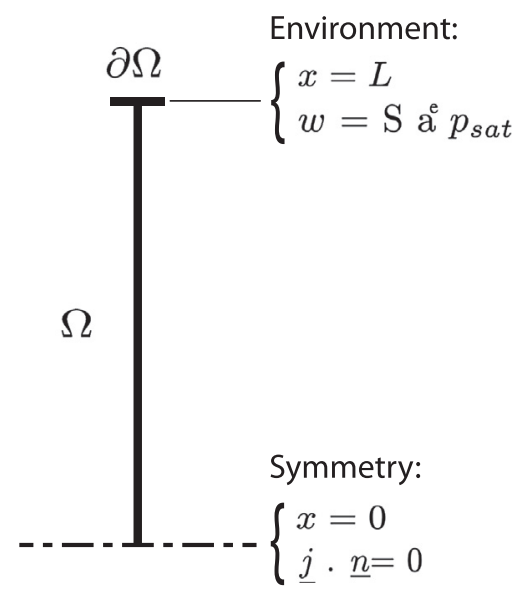

Fig. 9. Boundary conditions applied for the 1D simulations of diffusion and reaction processes in a one dimensional domain. 


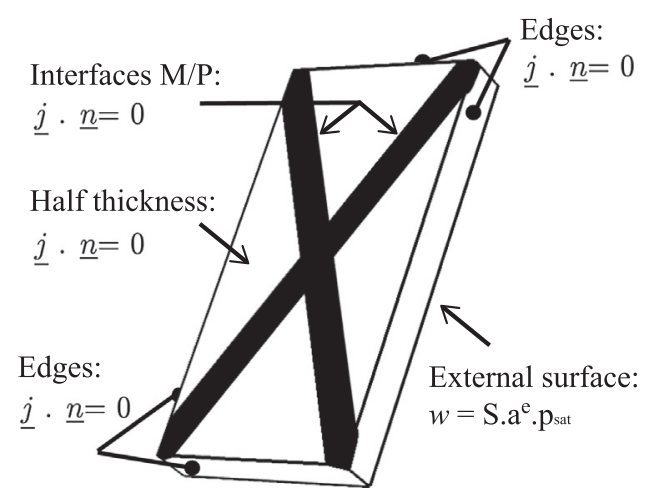

Fig. 10. Boundary conditions applied for the 3D simulations of diffusion and reaction processes in a periodic cell of a metal/polymer composite.

were found to be negligible. The whole $3 \mathrm{D}$ domain $(\Omega)$ was split into two sub-domains, $\Omega_{p}$ and $\Omega_{m}$, the polymer matrix and the metal foil respectively. We used the same model parameters for the epoxy in neat epoxy samples and metal/epoxy samples (Table 1). We used an extra fine mesh with about 20 thousands second-order tetrahedral finite elements.

Similarly to the $1 \mathrm{D}$ case, symmetry boundary condition was applied at the half thickness and a Dirichlet boundary condition (Eq. (15)) was specified at the external surface exposed to the humid environment.

Zero flux boundary conditions were applied at the four edges as per the periodicity of the cell. The normal components of the mass flux at the interface between the two sub-domains, the polymer $\left(\Omega_{p}\right)$ and the metal $\left(\Omega_{m}\right)$, were set to zero.

Initial conditions for $w$ and $Y$ were identical to those prescribed in Eq. (16), whereas the reactive substrate $(R)$ was defined only in $\Omega_{p}$ (Eq. (17)):

$R=R_{0} \quad \forall \underline{M} \in \Omega_{p}, \quad t=0$

\section{Results and discussions}

Our aim was to investigate the physical basis of the proposed diffusion-reaction model as well as the accuracy of the numerical simulations of water transport in epoxy matrices.

\subsection{Experimental evidence of hydrolysis reaction}

We conducted both FTIR and SEM analyses to track chemical and microstructural changes in the polymer at several aging times (Fig. 8). Our SEM images did not reveal any microstructural changes. We therefore focused the investigation on chemical changes.

In the anhydride-cured epoxy system considered here, three species are potentially hydrolysed during moisture sorption, the anhydride, the ester or the epoxy. We need, at first, to identify which of these groups were present before the start of the sorption experiment. Here, the epoxy/anhydride mass ratio was 0.93 , which corresponds to a functional ratio epoxy/anhydride of 0.95 . There is excessive anhydride, as confirmed by the presence of the IR peak at $1771 \mathrm{~cm}^{-1}$ in dry samples (Fig. 11). The spectrum of virgin samples displays also a peak at $915 \mathrm{~cm}^{-1}$ that can result from the overlapping of several species among which anhydride groups and the eventually unreacted epoxy (the anhydride-epoxy reaction is equilibrated and therefore never complete).

To investigate spectral changes during aging, we used the aromatic peak at $1508 \mathrm{~cm}^{-1}$ as the reference peak since aromatic

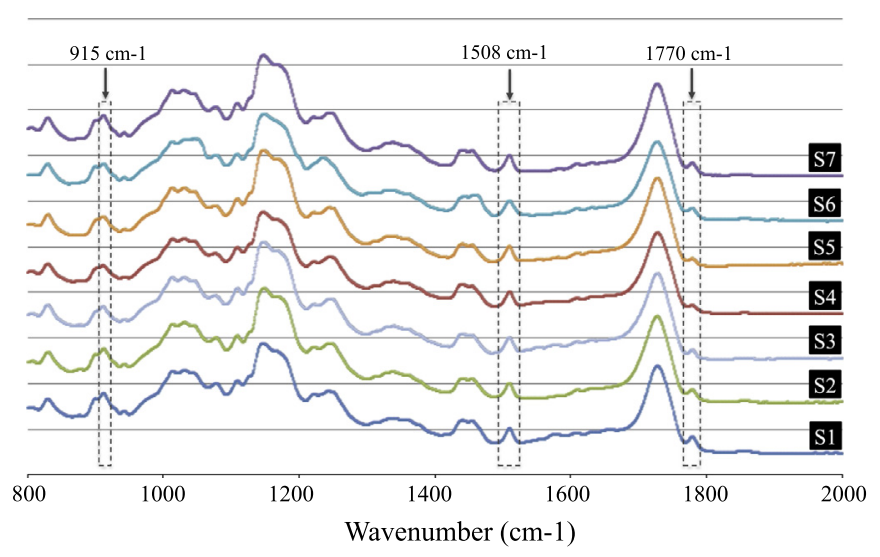

Fig. 11. Changes in the IR spectra of the epoxy resin during sorption/desorption experiments. (For interpretation of the references to color in this figure legend, the reader is referred to the web version of this article.)

groups are expected to be unreactive with water and stable at the temperature under study [24,22]. A relative peak intensity was then defined according to Eq. (18):

$E^{\text {band }}(t)=\frac{A^{\text {band }}(t) / A^{1508}(t)}{A^{\text {band }}(t=0) / A^{1508}(t=0)}$

where $A^{\text {band }}$ is the area of a given band $\left(915 \mathrm{~cm}^{-1}, 1771 \mathrm{~cm}^{-1}\right.$, etc.) and $A^{1508}$ is the area of the band at $1508 \mathrm{~cm}^{-1}$.

The relative changes of peak absorbances at $1771 \mathrm{~cm}^{-1}$ and $915 \mathrm{~cm}^{-1}$ during the sorption-desorption experiment are depicted in Fig. 12. For both peaks, the absorbance first decreases during the initial period of continuous exposure to humidity and increases slowly during the desorption stage. Both relative absorbances remain linked by a linear relationship (Eq. (19)):

$E^{915}=0.36 \times E^{1771}+0.66$

Changes in the area under the peak centered at $1730 \mathrm{~cm}^{-1}$, where esters initially present in the cycloaliphatic epoxy component (peak at $1728 \mathrm{~cm}^{-1}$ ) coexist with esters resulting from the epoxideanhydride reaction (peak at $1733 \mathrm{~cm}^{-1}$ ), are depicted in Fig. 12(b). This Figure shows that no change in the absorbance is noticeable in the ester region during the sorption-desorption experiment.

These results can be interpreted as follows. Water reacts mainly with the anhydride groups in the timescale under consideration according to the following scheme (Eq. (20)):

$\mathrm{P}-\mathrm{CO}-\mathrm{O}-\mathrm{CO}-\mathrm{P}+\mathrm{H}_{2} \mathrm{O} \leftrightarrow 2 \mathrm{PCO}-\mathrm{OH}$

Because the reaction is equilibrated, the resulting diacid recondensates into anhydride when the water concentration decreases during a dry period. According to this mechanism, the sample's mass is expected to increase by $18 \mathrm{~g}$ per mole of hydrolysis event during humid exposure and to decrease by $18 \mathrm{~g}$ per mole of condensation event during dry exposure. The reaction kinetics are function of the concentrations of the reactants and the product and of the two rate constants $\left(k_{h}\right.$ for the forward reaction, $k_{r}$ for the reverse one) (Eqs. (8)-(10)).

The change in peak absorbance at $915 \mathrm{~cm}^{-1}$ is due exclusively to a change of its anhydride component, which corresponds initially to only $36 \%$ of the total absorbance, the rest being presumably due to eventually present epoxide groups and other unidentified polymer bands. These species, whatever their nature, do not react with water in the timescales under consideration. 


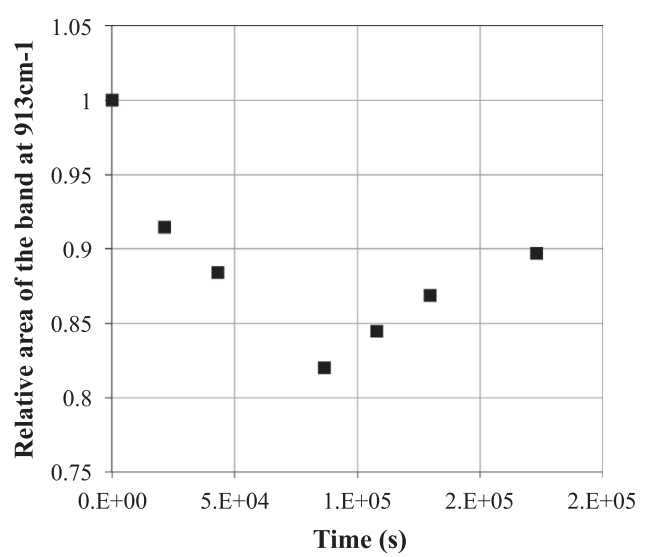

(a) $913 \mathrm{~cm}^{-1}$

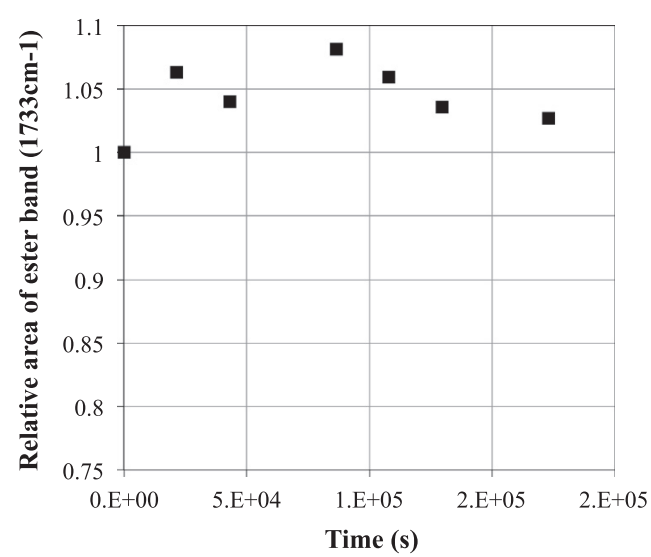

(b) $1733 \mathrm{~cm}^{-1}$

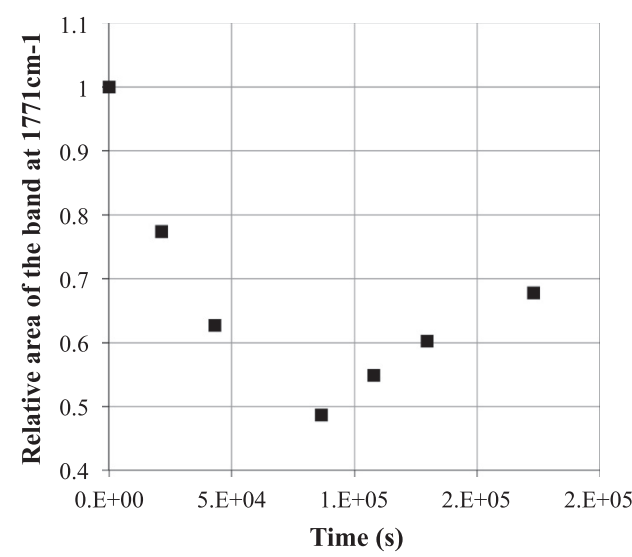

(c) $1771 \mathrm{~cm}^{-1}$

Fig. 12. Changes in the area under the $I R$ peaks $\left(915,1733\right.$ and $\left.1771 \mathrm{~cm}^{-1}\right)$ during sorption and desorption experiments.

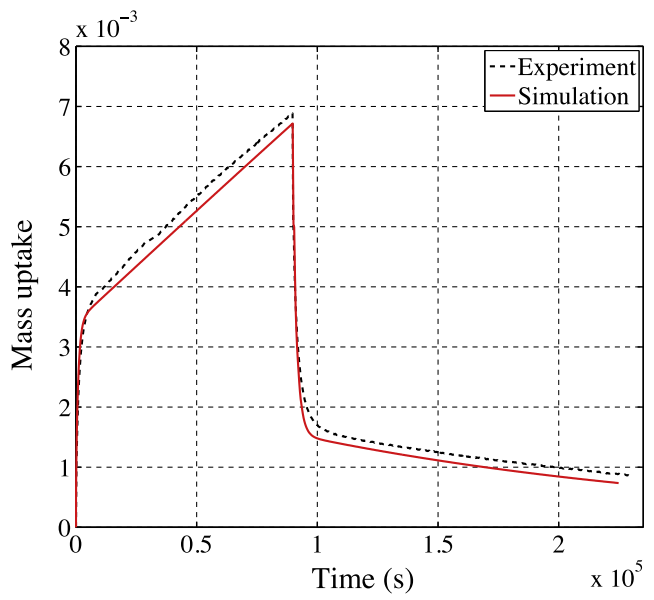

(a) Aluminum/Epoxy

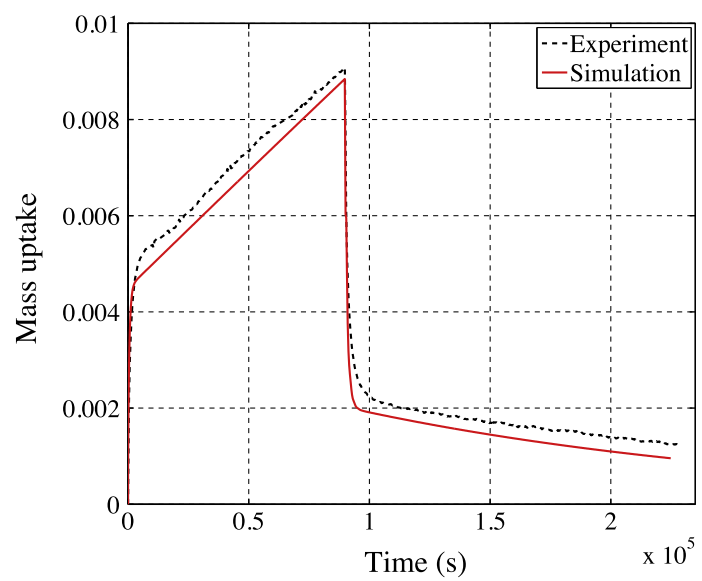

(b) Copper/Epoxy

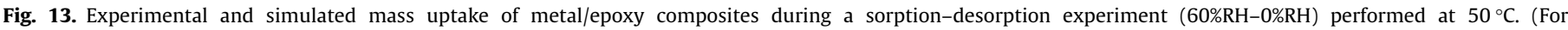
interpretation of the references to color in this figure legend, the reader is referred to the web version of this article.)

\subsection{Simulation of water transport in composite materials}

We first consider metal/epoxy composites exposed to sorptiondesorption conditions. Fig. 13 shows a comparison of the experimental and simulated mass uptake of the two types of composite materials previously described. In both cases, the proposed model yields accurate simulations. Fig. 14 shows the simulated 3D distribution of the total concentration of water in the polymer matrix. The local concentration of water can then be used to calculate the mechanical and hydric strain fields. We note that the simulations are satisfying without specifying any particular law at the interface although the aging behavior of the interphase could be quite complex because of the local heterogeneities reported in the literature [25]. In fact, the metal/epoxy interface 


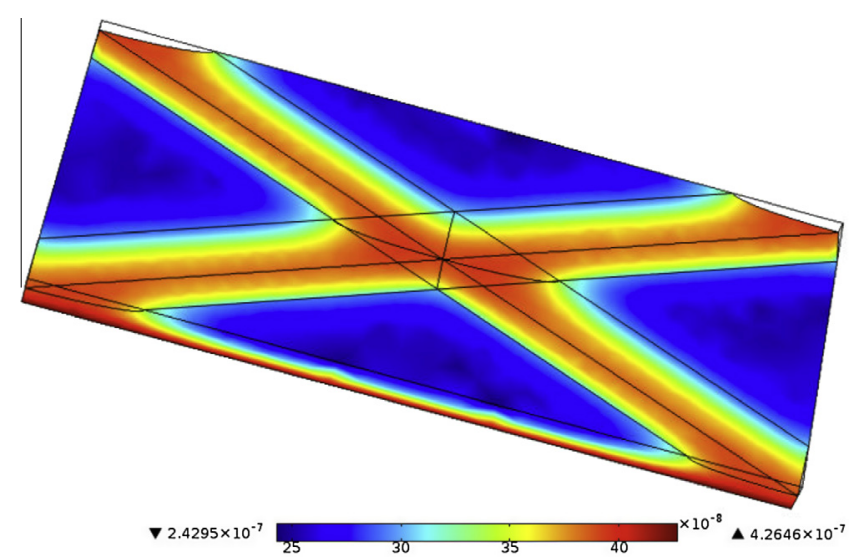

Fig. 14. Simulation of the water transport in the matrix of an aluminum/epoxy composite. (For interpretation of the references to color in this figure legend, the reader is referred to the web version of this article.)

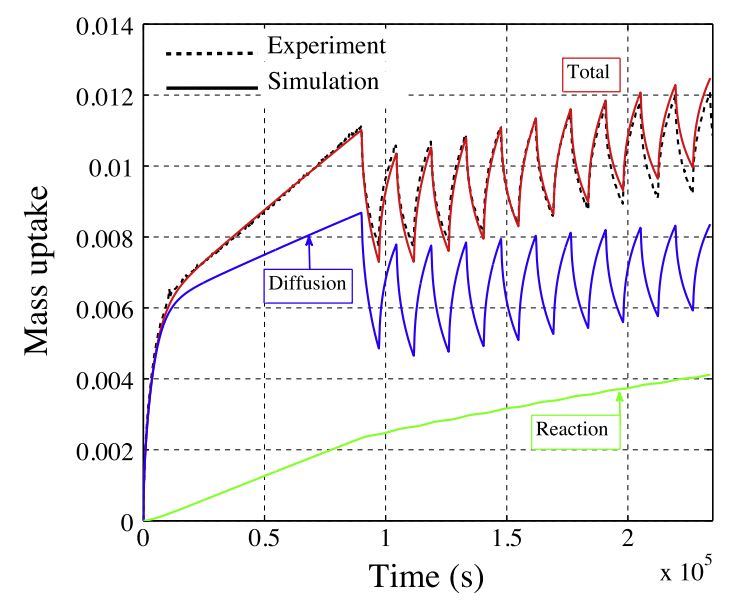

Fig. 15. Experimental and simulated change in the mass uptake of neat epoxy during under cyclic humidity conditions (between $20 \% \mathrm{RH}$ and $60 \% \mathrm{RH}$ ) performed at $50{ }^{\circ} \mathrm{C}$. (For interpretation of the references to color in this figure legend, the reader is referred to the web version of this article.)

appears to be a barrier to the mass flux from the global viewpoint and regardless to the nature of the metal. This could be explained by the orientation of the mass flux, which is here mainly normal to the interface. In the case where the moisture diffuses in a parallel plane to the metal expanded foil, the role of the interface would certainly be more crucial. A more appropriate approach is required to investigate the role and the degradation of the interphase. For this purpose, a specific model needs to be developed to account for the higher diffusivity of the interphase and to predict its aging when the concentrations of the diffusing water and the reacted species are known at the interface. The proposed model can provide the local concentrations in the matrix surrounding the interphase, which can feed the more specific interphase model.

\subsection{Simulation of water transport in a dynamic regime}

We also consider a homogeneous epoxy specimen exposed to cyclic humidity conditions. It should be noted that this validation test is not common, despite the real interest for industrial applications. Fig. 15 shows the experimental and simulated global mass uptake as well as the simulated contributions of diffusion and reaction. From the global viewpoint, the simulations are in good agreement with the experiments.
The amount of diffusing water (Fig. 15) oscillates at the same frequency as the cyclic relative humidity. Hence, the amplitude of variations in the global mass uptake is entirely due to the transport of the diffusing water and is about $0.3 \%$. This leads to a strain amplitude equal to $\Delta \varepsilon=0.12 \%$, with a coefficient of hydric expansion about $0.4 \%$ of strain per mass percent, as determined by the authors in [26].

As for the contribution of the reaction, the overall amount of reacted water increases linearly in the dynamic regime. This can be expected because the characteristic time of the reaction is much longer than the duration of one cycle. Also, the apparent reaction rate in the dynamic regime is about half of its value in the static regime, which is due to the decrease in the average value of the diffusing water concentration.

\section{Conclusion}

We studied the physical foundations of the diffusion-reaction model as well as the accuracy of the numerical simulations of water transport in epoxy matrices. The material under study was an anhydride-cured epoxy system that displays a non-Fickian sorption behavior. We performed FTIR analysis and microstructural observations at different times during sorption and desorption. In addition, we studied the sorption-desorption behavior of hybrid metal/epoxy samples, as well as moisture uptake in the dynamic regime.

We found that Scanning Electron Microscopy did not reveal any microstructural changes. Yet, we evidenced that the polymer matrix undergoes hydrolysis reaction. FTIR revealed that the predominant mechanism is the hydrolysis of the residual anhydride groups. Finally, our proposed model is able to provide accurate simulations of water transport in the epoxy matrix, even under complex cycling conditions and with heterogeneous materials.

\section{References}

[1] Gardiner G. Lightning strike protection for composite structures. High Perform Compos 2006; July:44-9.

[2] Ventura I, Rahaman A, Lubineau G. The thermal properties of a carbon nanotube-enriched epoxy: thermal conductivity, curing, and degradation kinetics. J Appl Polym Sci 2013;130:2722-33.

[3] Lubineau G, El Yagoubi J, Saghir S, Selvakumaran L. Cyclic hygrothermal aging of aircraft lightning protections: phenomenological overview. In: 53rd AIAA/ ASME/ASCE/AHS/ASC structures, structural dynamics, and materials conference; 2012.

[4] De Neve B, Shanahan M. Water absorption by an epoxy resin and its effect on the mechanical properties and infra-red spectra. Polymer 1993:34:5099-105.

[5] Alessi S, Conduruta D, Pitarresi G, Dispenza C, Spadaro G. Accelerated ageing due to moisture absorption of thermally cured epoxy resin/polyethersulphone blends. Thermal, mechanical and morphological behavior. Polym Degrad Stab 2011;96:642-8.

[6] McKague E, Reynolds J, Halkias J. Swelling and glass transition relations for epoxy matrix material in humid environments. J Appl Polym Sci 1978;22: $1643-54$.

[7] Perrin F, Nguyen M, Vernet J. Water transport in epoxy-aliphatic amine networks - influence of curing cycles. Eur Polym J 2009;45:1524-34.

[8] Adamson M. Thermal expansion and swelling of cured epoxy resin used in graphite/epoxy composite materials. J Mater Sci 1980;15:1736-45.

[9] Antoon M, Koenig J. Irreversible effects of moisture on the epoxy matrix in glass-reinforced composites. J Polym Sci B 1981;19:197-212.

[10] Leger R, Roy A, Grandidier J. Non-classical water diffusion in an industrial adhesive. Int J Adhes Adhes 2010;30:744-53.

[11] Crank J. The mathematics of diffusion. 2nd ed.; 1975.

[12] Carter H, Kibler K. Langmuir-type model for anomalous moisture diffusion in composite resins. J Compos Mater 1978;12:118-31.

[13] Wong T, Broutman L. Moisture diffusion in epoxy resins. Part II: Diffusion mechanism. Polym Eng Sci 1985;25(9):529-34.

[14] Weitsman Y. A continuum diffusion model for viscoelastic materials. J Phys Chem 1990;94:961-8.

[15] Tcharkhtchi A, Bronnec P, Verdu J. Water absorption characteristics of diglycidylether of butane diol-3,5-diethyl-2,4-diaminotoluene networks. Polymer 2000;41:5777-85.

[16] Popineau S, Rondeau-Mouro C, Sulpice-Gaillet C, Shanahan M. Free-bound water absorption in an epoxy adhesive. Polymer 2005;46:10733-40. 
[17] Zhou J, Lucas J. Hygrothermal effects of epoxy resin. Part I: The nature of water in epoxy. Polymer 1999;40:5505-12.

[18] Antoon M, Koenig J. Fourier-transform infrared study of the irreversible interaction of water and a crosslinked epoxy matrix. J Polym Sci B 1981;19:1567-75.

[19] Célino A, Gonçalves O, Jacquemin F, Fréour S. Qualitative and quantitative assessment of water sorption in natural fibres using ATR-FTIR spectroscopy. Carbohydr Polym 2014;101(0):163-70.

[20] Partini M, Pantani R. FTIR analysis of hydrolysis in aliphatic polyesters. Polym Degrad Stab 2007;92:1491-7.

[21] El Yagoubi J, Lubineau G, Roger F, Verdu J. A fully coupled diffusion-reaction scheme for moisture sorption-desorption in an anhydride-cured epoxy resin. Polymer 2012;1:11-5.
[22] Lin Y, Chen X, Zhang H, Wang Z. Effects of hygrothermal aging on epoxy-based anisotropic conductive film. Mater Lett 2006;60:2958-63.

[23] Vanlandingham M, Eduljee R, Gillespie J. Relationships between stoichiometry microstructure, and properties for amine-cured epoxies. J Appl Polym Sc 1999;71:699-712.

[24] Cherdoud-Chihani A, Mouzali M, Abadie M. Study of crosslinking ams/DGEBA system by FTIR. J Appl Polym Sci 1997;69:1167-78.

[25] Boerio F, Ondrus D. Effect of substrates on the structure of polyme interphases: II. Epoxyanhydride adhesives cured against aluminum and copper. J Colloid Interface Sci 1990;139(2):446-56.

[26] El Yagoubi J, Lubineau G, Saghir S, Verdu J, Askari A. Thermomechanical and hygroelastic properties of an epoxy system under humid and cold-warm cycling conditions. Polym Degrad Stab 2014;99:146-55. 